\title{
Exercise is medicine for patients with major depressive disorders: but only if the "pill" is taken!
}

This article was published in the following Dove Press journal:

Neuropsychiatric Disease and Treatment

5 August 2016

Number of times this article has been viewed

\author{
Markus Gerber' \\ Edith Holsboer-Trachsler ${ }^{2}$ \\ Uwe Pühse ${ }^{3}$ \\ Serge Brand ${ }^{1,2}$ \\ 'Department of Sport, Exercise \\ and Health, Division of Sport and \\ Psychosocial Health, University of \\ Basel, ${ }^{2}$ Center for Affective, Stress \\ and Sleep Disorders, Psychiatric \\ Clinics of the University of Basel, \\ ${ }^{3}$ Department of Sport, Exercise and \\ Health, Division of Sport and Health \\ Pedagogy, University of Basel, Basel, \\ Switzerland
}

\begin{abstract}
Major depressive disorders (MDDs) are a widespread and burdensome mental illness associated with a high comorbidity with other conditions and a significantly reduced life expectancy compared to the general population. Therefore, targeted actions are needed to improve physical health in people with MDDs, in addition to ongoing efforts to enhance psychological well-being. Meanwhile, the positive effects of exercise training on the treatment of MDDs are well documented, while compelling evidence exists that exercise interventions can improve cardiorespiratory fitness in clinically meaningful ways. On the flipside, the longterm effects of exercise therapy are still not well documented, and recent studies suggest that initial improvements in MDDs dissipate if regular exercise participation is discontinued after the end of interventions. A recent survey among Swiss psychiatric hospitals further shows that all institutions provide some form of physical activity and exercise program. However, only a limited number of patients participate in these programs, mainly because participation is voluntary and no particular efforts are undertaken to engage patients with the lowest physical activity levels. We argue that more systematic efforts are needed to fully exploit the potential of physical activity and exercise programs in psychiatric care. We also emphasize that initiating and maintaining regular physical activity among psychiatric patients is a major challenge because specific dysfunctional cognitive-emotional processes might interfere with their capacity to self-regulate health-related behaviors. Specifically, we claim that behavioral skill training should be used to support patients with MDDs in overcoming barriers to initiating and maintaining physical activity. Moreover, we suggest that the assessment of physical activity and cardiorespiratory fitness should become routine in psychiatric practice.
\end{abstract}

Keywords: depression, counseling, comorbidities, fitness, physical activity, self-regulation

\section{Discussion}

Major depressive disorders (MDDs) are a widespread and burdensome mental illness. ${ }^{1,2}$ According to the WHO Global Burden of Disease study, MDDs are the condition with the second greatest number of life years lost due to premature death or disability ${ }^{3}$ and are projected to be the leading cause in $2030 .{ }^{4}$ Moreover, MDDs are the leading cause of years of life lived with disability in men and women. ${ }^{5}$

MDDs are closely linked with poor quality of life, increased medical expenditures, and elevated utilization of health care services. ${ }^{6}$ Moreover, they are characterized by a high comorbidity with other mental and physical conditions. For instance, people with depression have a two- to fourfold risk for developing metabolic conditions and cardiovascular diseases. ${ }^{7-10}$ Several putative mechanisms have been proposed to link MDDs and other medical conditions, including the hypothalamic-pituitary-adrenal axis and sympathomedullary hyperactivity, increased platelet reactivity, reduced heart rate variability, vascular inflammation, oxidative stress, and endothelial dysfunction. ${ }^{10,11}$
Correspondence: Markus Gerber Department of Sport, Exercise and Health, Division of Sport and Psychosocial Health, University of Basel, Birsstrasse 320, 4052 Basel, Switzerland Tel +4I 613778783

Fax +4I 6I 3778783

Email markus.gerber@unibas.ch 
Other possible factors are lower receipt of high-quality physical health care, reduced compliance with medical recommendations, adverse medication treatment effects, or the presence of modifiable behavioral risk factors such as physical inactivity.?

As a consequence, people with MDDs have an increased risk for premature mortality if compared with the general population, ${ }^{12,13}$ resulting in a life expectancy of $\sim 10-15$ years shorter than that of the general population. ${ }^{13}$ Although these disparities have been recognized since the mid-1980s, this life expectancy gap has widened during the last 30 years. ${ }^{14}$ Targeted actions are therefore needed to improve physical health in people with MDDs, in addition to ongoing efforts to enhance psychological well-being.

While the standard treatment of MDDs is medication, psychotherapy, or a combination of both, the effectiveness of these treatments is mixed. With regard to medication-oriented approaches, it has been estimated that only $\sim 30 \%-50 \%$ of all patients show a response to treatment with single-action or dual-action antidepressant monotherapy, ${ }^{15,16}$ whereas remission is found in an even smaller portion of participants $(15 \%-40 \%) .^{16,17}$ Hence, $>50 \%$ of all patients do not respond adequately. Therefore, a switch or augmentation in medication is necessary for many patients. ${ }^{6}$ However, even these additional treatments often do not result in remission. ${ }^{18}$ As a consequence, complementary nonpharmacological treatment options are highly warranted from a public health perspective. ${ }^{19}$

In several countries, health foundations have encouraged general practitioners to prescribe exercise as a frontline strategy in the treatment of MDDs..$^{20,21}$ Meanwhile, several meta-analyses have supported that exercise interventions are able to increase response/remission compared with no treatment or placebo conditions in clinically depressed patients. ${ }^{20-28}$ For instance, Josefsson et a ${ }^{28}$ found a relatively strong effect (Hedges $g=-0.77$ ) in favor of exercise treatment, which, however, decreased to a moderate effect if only studies with high methodological standards were considered (eg, allocation concealment, blinded outcome assessment, and intention-to-treat analysis). Nevertheless, Schuch et a ${ }^{26}$ recently concluded that the effects of exercise might have been underestimated due to publication bias.

Beyond these meta-analyses, studies have shown that exercise therapy might be a worthwhile add-on to standard care, ${ }^{29}$ that exercise is successful in reducing even treatmentresistant depression, ${ }^{30}$ and that single bouts of exercise have favorable neurobiological effects. ${ }^{31}$ Importantly, a meta-analysis showed that exercise interventions have the capacity to improve cardiorespiratory fitness in people with
MDDs in clinically meaningful ways. ${ }^{32}$ Based on seven randomized controlled trials, Stubbs et a ${ }^{32}$ reported an overall effect size of 0.64 (corresponding to a mean increase of $3.05 \mathrm{~mL} / \mathrm{kg} / \mathrm{min}$ of oxygen uptake). This is relevant because improvements of $3.5 \mathrm{~mL} / \mathrm{kg} / \mathrm{min}$ in $\mathrm{VO}_{2}$ max are related to a $13 \%$ and $15 \%$ decrease in cardiovascular disease and allcause mortality, respectively, in the general population. ${ }^{33}$

In two further studies, Blumenthal et $\mathrm{al}^{34,35}$ compared the effectiveness of 4-month aerobic exercise program with pharmacotherapy in 156 older patients and 202 adults with MDDs. Both studies showed that exercise is equally effective in reducing depressive symptoms similar to antidepressant medication. Furthermore, the latter study demonstrated that remission rates are higher with antidepressants or exercise compared with a placebo control condition. ${ }^{35}$

While these findings are promising, the long-term effects of exercise therapy are still not well documented, which dampens the notion that "exercise is medicine" in this group of patients ("Exercise is Medicine ${ }^{\circledR}$ [EIM]" is a campaign managed by the American College of Sports Medicine [ACSM]. With its global health initiative, the ACSM intends to encourage primary care physicians and other health care providers to include physical activity when designing treatment plans for patients. Moreover, EIM emphasizes that physical activity plays an important role in the prevention and treatment of diseases, and therefore, as part of all health care, should be routinely assessed and treated). In this regard, a recent study found that initial improvements in MDD dissipate if regular exercise participation is discontinued after the end of interventions. ${ }^{36}$ Thus, Hoffman et $\mathrm{al}^{36}$ showed that neither group assignment (exercise vs pharmacotherapy) nor antidepressant medication usage during the follow-up period was associated with response or remission at 12-month follow-up. The only significant predictor was regular exercise during the follow-up period, showing that patients who exercised regularly after completion of the initial treatment had a lower likelihood of depression at follow-up. These results support the findings of a previous study with older adults, in which regular posttreatment exercise was associated with a $50 \%$ reduced relapse rate at 6 -month follow-up. ${ }^{37}$

Given these findings, integrating exercise as an add-on to standard care ${ }^{38}$ and efforts to promote lifestyle physical activity to prevent relapses after the end of in- or out-patient treatment seem necessary. In line with this notion, in a survey among all 55 psychiatric hospitals of the Germanspeaking part of Switzerland, which was recently published in Neuropsychiatric Disease and Treatment, Brand et al ${ }^{39}$ showed that all hospitals provided some form of physical activity and 
exercise program, including sports therapy, activity-related psychotherapeutic interventions, physiotherapy, and body therapies. While this is encouraging and highlights that the potential of physical activity and exercise is increasingly recognized in psychiatric care, the fact that only $25 \%$ of patients participated in these programs is critical. Given that across all hospitals, participation in these programs was voluntary and that no particular efforts are undertaken to engage those patients with the lowest physical activity levels, the likelihood to reach the patients who presumably would benefit most from increased physical activity and exercise is limited.

We therefore argue that systematic efforts and concerted actions are needed in order to fully exploit the potential of physical activity and exercise programs in psychiatric care. Moreover, we emphasize that initiating and maintaining regular physical activity among psychiatric patients is a major challenge. For instance, among patients with MDDs, specific dysfunctional cognitive-emotional processes might interfere with their motivation and capacity to self-regulate health-related behaviors. Studies have shown that MDDs are linked with motivational and volitional deficits in all areas of daily life due to feelings of hopelessness, pessimism, and a tendency to postpone tasks. ${ }^{40}$ Not surprisingly, MDDs are associated with decreased exercise-related self-efficacy, increased negative outcome expectations, reduced exercise intentions, and increased perception of situational barriers. ${ }^{41}$ Despite these challenges, Mota-Pereira et $\mathrm{al}^{30}$ were able to show that very high compliance to an exercise program $(<90 \%)$ can be achieved even in patients with treatmentresistant MDDs if behavioral techniques (eg, techniques reminding the participants to exercise) are promoted as an integral part of the exercise intervention.

Given this background, we claim that major therapeutic efforts are required to decrease the unfavorable cognitiveemotional processes experienced by patients with MDDs, in order to support them in overcoming barriers to initiating and maintaining physical activity. Moreover, we suggest that the assessment of physical activity and cardiorespiratory fitness, in close relation to symptom severity, should become routine in psychiatric practice. We further claim that research into the potential of lifestyle physical activity counseling to increase patients' behavior skills (eg, action planning, coping with exercise-related barriers, social support) should become a top priority in patients with MDDs. Integrating such interventions, which proved to work well among patients suffering from somatic conditions, ${ }^{42-45}$ would clearly strengthen the notion of "exercise is medicine" in this specific patient population.
Moreover, improved relapse management by emphasizing that exercise is a fluctuating behavior and that alternations between more and less physically active periods are normal for most people can help prevent negative consequences in terms of reduced self-efficacy and hopelessness if patients with MDDs who have participated in structured exercise programs feel unable to continue with their exercise regime. Finally, although it is still difficult to say what kind of physical activity or exercise works best against major depression, ${ }^{46} \mathrm{a}$ previous study showed that public health doses seem to be necessary to achieve positive effects. ${ }^{19}$ Furthermore, in line with the Dual-Mode Theory of affective responses, ${ }^{47}$ research consistently shows that affective responses during exercise are more positive and homogeneous at moderate intensity levels, whereas more variability occurs at heavier intensities (due to a stronger influence of cognitive factors such as self-efficacy and self-presentational concerns). ${ }^{48,49}$ However, fostering favorable emotions during exercise is important because they can facilitate the development of positive implicit attributions that play an important role in the regulation of exercise behavior. ${ }^{50,51}$ Thus, while we acknowledge that specific forms of high-intensity exercise training may have positive effects on cardiorespiratory fitness, ${ }^{52}$ we argue that moderate-intensity exercise seems to be more promising to initiate long-term behavior change in patients with MDDs.

\section{Acknowledgment}

This correspondence was written without external funding.

\section{Disclosure}

The authors report no conflicts of interest in this work.

\section{References}

1. Kessler RC, Berglund P, Demler O, et al; National Comorbidity Survey Replication. The epidemiology of major depressive disorder. Results from the national comorbidity survey replication. JAMA. 2003;18(23): 3095-3105.

2. Kessler RC, Berglund P, Demler O, Jin R, Merikangas KR, Walters EE. Lifetime prevalence and age-of-onset distributions of DSM-IV disorders in the national comorbidity survey replication. Arch Gen Psychiatry. 2005;62(6):593-602.

3. Murray CJ, Lopez AD. Global mortality, disability, and the contribution of risk factors: global burden of disease study. Lancet. 1997;349(9063): 1436-1442.

4. Lépine J-P, Briley M. The increasing burden of depression. Neuropsychiatr Dis Treat. 2011;7(suppl 1):3-7.

5. World Health Organization. The World Health Report 2001-Mental Health: New Understanding, New Hope. Geneva: World Health Organization; 2001.

6. Blumenthal JA, Smith PJ, Hoffman BM. Is exercise a viable treatment for depression? ACSMs Health Fit J. 2012;16(4):14-21.

7. Vancampfort D, Mitchell AJ, De Hert M, et al. Type 2 diabetes in patients with major depressive disorder: a meta-analysis of prevalence estimates and predictors. Depress Anxiety. 2015;32(10):763-773. 
8. Luppino FS, de Wit LM, Bouvy PF, et al. Overweight, obesity, and depression: a systematic review and meta-analysis of longitudinal studies. Arch Gen Psychiatry. 2010;67(3):220-229.

9. Pan A, Sun Q, Okereke OI, Rexrode KM, Hu FB. Depression and risk of stroke morbidity and mortality: a meta-analysis and systematic review. JAMA. 2011;306(11):1241-1249.

10. Dhar AK, Barton AD. Depression and the link with cardiovascular disease. Front Psychiatry. 2016;7:1-9.

11. Goldstein BI, Carnethon MR, Matthews KA, et al; American Heart Association Atherosclerosis, Hypertension and Obesity in Youth Committee of the Council on Cardiovascular Disease in the Young. Major depressive disorder and bipolar disorder predispose youth to accelerated atherosclerosis and early cardiovascular disease: a scientific statement from the American Heart Association. Circulation. 2015;132(10): 965-986.

12. Cuijpers P, Vogelzangs N, Twisk J, Kleiboer A, Li J, Penninx BW. Differential mortality rates in major and subthreshold depression: metaanalysis of studies that measured both. Br J Psychiatry. 2013;202(1): 22-27.

13. Walker ER, McGee RE, Druss BG. Mortality in mental disorders and global disease burden implications: a systematic review and metaanalysis. JAMA Psychiatry. 2015;72(4):334-341.

14. Thornicroft G. Physical health disparities and mental illness: the scandal of premature mortality. Br J Psychiatry. 2011;199(6):441-442.

15. Smith D, Dempster C, Glanville J, Feemantle N, Anderson I. Efficacy and tolerability of venlafaxine compared with selective serotonin re-uptake inhabitors and other antidepresssants: a meta-analysis. Br J Psychiatry. 2002;180:396-404.

16. Trivedi MH, Daly EJ. Treatment strategies to improve and sustain remission in major depressive disorder. Dialogues Clin Neurosci. 2008; 10(4):377-384.

17. Nemeroff $\mathrm{CB}$. Prevalence and management of treatment-resistant depression. J Clin Psychiatry. 2007;68(suppl 8):17-25.

18. Trivedi MH, Fava M, Wisniewski SR, et al; STAR*D Study Team. Medication augmentation after the failure of SSRIs for depression. N Engl J Med. 2006;354(12):1243-1252.

19. Dunn AL, Trivedi MH, Kampert JB, Clark CG, Chambliss HO. Exercise treatment for depression: efficacy and dose response. Am J Prev Med. 2005;28(1): 1-8

20. Rethorst CD, Wipfli BM, Landers DM. The antidepressive effects of exercise: a meta-analysis of randomized trials. Sports Med. 2009; 39(6):491-511.

21. Lawlor DA, Hopker SW. The effectiveness of exercise as an intervention in the management of depression: systematic review and metaregression analysis of randomised controlled trials. BMJ. 2001; 322(7289):763-767.

22. Krogh J, Nordentoft M, Sterne JA, Lawlor DA. The effect of exercise in clinically depressed adults: systematic review and meta-analysis of randomized controlled trials. J Clin Psychiatry. 2011;72(4):529-538.

23. Craft LL, Landers DM. The effect of exercise on clinical depression and depression resulting from mental illness: a meta-analysis. $J$ Sport Exerc Psychol. 1998;20:339-357.

24. Stathopoulou G, Powers MB, Berry AC, Smits JAJ, Otto MW. Exercise interventions for mental health: a quantitative and qualitative review. Clin Psychol Sci Pract. 2006;13(2):179-193.

25. Mead GE, Morley D, Campbell P, Greig CA, McMurdo MET, Lawlor DA. Exercise for depression. Cochrane Database Syst Rev. 2009;4: CD004366.pub3.

26. Schuch FB, Vancampfort D, Richards J, Rosenbaum S, Ward PB, Stubbs B. Exercise as a treatment for depression: a meta-analysis adjusting for publication bias. J Psychiatr Res. 2016;77:42-51.

27. Cooney GM, Dwan K, Greig CA, et al. Exercise for depression. Cochrane Database Syst Rev. 2013;9:CD004366.pub6.

28. Josefsson T, Lindwall M, Archer T. Physical exercise intervention in depressive disorders: meta-analysis and systematic review. Scand $J$ Med Sci Sports. 2014;24(2):259-272.
29. Schuch FB, Vasconcelos-Moreno MP, Borowsky C, Zimmermann AB, Rocha NS, Fleck MP. Exercise and severe major depression: effect on symptom severity and quality of life at discharge in an inpatient cohort. J Psychiatr Res. 2015;61:25-32.

30. Mota-Pereira J, Silverio J, Carvalho S, Ribeiro JC, Fonte D, Ramos J. Moderate exercise improves depression parameters in treatment-resistant patients with major depressive disorder. J Psychiatr Res. 2011;45(8): 1005-1011.

31. Schuch FB, Deslandes AC, Stubbs B, Gosmann NP, Silva CT, Fleck MP. Neurobiological effects of exercise on major depressive disorder: a systematic review. Neurosci Biobehav Rev. 2016;61:1-11.

32. Stubbs B, Rosenbaum S, Vancampfort D, Ward PB, Schuch FB. Exercise improves cardiorespiratory fitness in people with depression: a meta-analysis of randomized controlled trials. J Affect Disord. 2016; 190:249-253.

33. Kodama S, Saito K, Tanaka S, et al. Cardiorespiratory fitness as a quantitative predictor of all-cause mortality and cardiovascular events in healthy men and women: a meta-analysis. JAMA. 2009;301(19): 2024-2035.

34. Blumenthal JA, Babyak MA, Moore KA, et al. Effects of exercise training on older patients with major depression. Arch Intern Med. 1999; 159(19):2349-2356.

35. Blumenthal JA, Babyak MA, Doraiswamy PM, et al. Exercise and pharmacotherapy in the treatment of major depressive disorder. Psychosom Med. 2007;69(7):587-596.

36. Hoffman BM, Babyak MA, Craighead WE, et al. Exercise and pharmacotherapy in patients with major depression: one-year follow-up of the SMILE study. Psychosom Med. 2011;73(2):127-133.

37. Babyak M, Blumenthal JA, Herman S, et al. Exercise treatment for major depression: maintenance of therapeutic benefit at 10 months. Psychosom Med. 2000;62(5):633-638.

38. Schuch FB, Vasconcelos-Moreno MP, Borowsky C, Fleck MP. Exercise and severe depression: preliminary results of an add-on study. $J$ Affect Disord. 2011;133(3):615-618.

39. Brand S, Colledge F, Beeler N, et al. The current state of physical activity and exercise programs in German-speaking, Swiss psychiatric hospitals: results from a brief online survey. Neuropsychiatr Dis Treat. 2016;12:1309-1317.

40. Krämer L, Helmes AW, Bengel J. Understanding activity limitations in depression: integrating the concepts of motivation and volition from health psychology into clinical psychology. Eur Psychol. 2014;19(4):278-288.

41. Krämer LV, Helmes AW, Seelig H, Fuchs R, Bengel J. Correlates of reduced exercise behaviour in depression: the role of motivational and volitional deficits. Psychol Health. 2014;29(10):1206-1225.

42. Fuchs R, Göhner W, Seelig H. Effects of a standardized group intervention on physical exercise and health: the MoVo-concept. $J$ Phys Act Health. 2011;8(6):794-803.

43. Gerber M, Fuchs R, Pühse U. Der Einfluss eines Kurz-Interventionsprogramms (MoVo-Lisa) auf das Bewegungsverhalten und die Determinanten köperlich-sportlicher Aktivität bei übergewichtigen und fettleibigen Personen [Effects of a short exercise-intervention on sport participation and cognitive-behavioral antecedents of sport participation in a sample of overweight and obese individuals]. Z Gesundheitspsychol. 2010;18:159-169.

44. Sniehotta FF, Scholz U, Schwarzer R, Fuhrmann B, Kiwus U, Völler H. Long-term effects of two psychological interventions on physical exercise and self-regulation following coronary rehabilitation. Int J Behav Med. 2005;12(4):244-255.

45. Lippke S, Ziegelmann JP, Schwarzer R. Behavioral intentions and action plans promote physical exercise: a longitudinal study with orthopedic rehabilitation patients. $J$ Sport Exerc Psychol. 2004;26(3):470-483.

46. Singh NA, Stavrinos TM, Scarbeck Y, Galambos G, Liber C, Fiatarone Singh MA. A randomized controlled trial of high versus low intensity weight training versus general practitioner care for clinical depression in older adults. J Gerontol A Biol Sci Med Sci. 2005;60(6):768-776. 
47. Ekkekakis P, Hall EE, Petruzzello SJ. Variation and homogeneity in affective responses to physical activity of varying intensities: an alternative perspective on dose-response based on evolutionary considerations. J Sports Sci. 2005;23(5):477-500.

48. Schneider M, Dunn A, Cooper D. Affect, exercise, and physical activity among healthy adolescents. J Sport Exerc Psychol. 2009;31(6): 706-723.

49. Markowitz SM, Arent SM. The exercise and affect relationship: evidence for the dual-mode model and a modified opponent process theory. J Sport Exerc Psychol. 2010;32(5):711-730.
50. Bluemke M, Brand R, Schweizer G, Kahlert D. Exercise might be good for me, but I don't feel good about it: do automatic associations predict exercise behavior? J Sport Exerc Psychol. 2010;32(2):137-153.

51. Conroy DE, Hyde AL, Doerksen SE, Ribeiro NF. Implicit attitudes and explicit motivation prospectively predict physical activity. Ann Behav Med. 2010;39(2):112-118.

52. Biddle SJ, Batterham AM. High-intensity interval exercise training for public health: a big HIT or shall we HIT it on the head? Int J Behav Nutr Phys Act. 2015;12(1):95.

\section{Publish your work in this journal}

Neuropsychiatric Disease and Treatment is an international, peerreviewed journal of clinical therapeutics and pharmacology focusing on concise rapid reporting of clinical or pre-clinical studies on a range of neuropsychiatric and neurological disorders. This journal is indexed on PubMed Central, the 'PsycINFO' database and CAS, and is the official journal of The International Neuropsychiatric Association (INA). The manuscript management system is completely online and includes a very quick and fair peer-review system, which is all easy to use. Visit http://www.dovepress.com/testimonials.php to read real quotes from published authors.

Submit your manuscript here: http://www.dovepress.com/neuropsychiatric-disease-and-treatment-journal 